\title{
Perancangan Buku Visual Adat Istiadat Suku Batak Toba sebagai Bentuk Pelestarian Budaya
}

\author{
Angeline Claudia dan Baroto Tavip \\ Departemen Desain Produk Industri, Fakultas Arsitektur Desain dan Perencanaan, \\ Institut Teknologi Sepuluh Nopember (ITS) \\ e-mail: claangeline5@gmail.com; tavip.baroto@gmail.com
}

\begin{abstract}
Abstrak-Adat dan budaya Batak selama ini lebih banyak disebarkan melalui mulut ke mulut dan dampaknya lama kelamaan bisa menyebabkan kepunahan. Sehingga, adat dan budaya perlu dilestarikan secara tertulis agar informasi tentang adat tetap dapat diketahui oleh generasi penerusnya. Tujuan perancangan buku visual ini untuk menjelaskan dan memberi gambaran tentang adat istiadat Batak Toba sebagai bentuk pelestarian budaya. Metode yang digunakan dalam penelitian ini adalah metode deskriptif dengan pendekatan kualitatif melalui wawancara dengan Raja Adat, petenun ulos, pengukir gorga rumah adat, dan guru musik yang berlokasi di tanah Batak. Selain itu wawancara juga dilakukan kepada dosen antropologi UI (Universitas Indonesia) dan pihak penerbit GPU (Gramedia Pustaka Utama). Pengumpulan data juga dilakukan melalui studi etnografi dan riset AEIOU (activity, environment, interaction, object, dan user) dengan mengunjungi situs budaya dan perkampungan adat di Pulau Samosir untuk mendapatkan data visual sekaligus mengamati proses adat yang terjadi di lokasi secara langsung. Sebagai data sekunder, dilakukan pula kajian pustaka terhadap buku-buku yang berkaitan dengan adat suku Batak Toba. Hasil dari perancangan ini adalah buku visual adat istiadat Batak Toba yang terdiri dari 6 topik yaitu sejarah, marga, upacara adat, ulos, rumah adat,dan kesenian. Penyajian konten dan visual dalam buku menggunakan jenis fotografi still life untuk menunjukkan artefak suku Batak, foto lanskap untuk menggambarkan keindahan tanah Batak, foto jurnalistik dan potrait untuk menunjukkan proses kegiatan adat dan masyarakat Batak Toba serta teknik digital imaging untuk menggabungkan dua atau lebih foto dalam rangka merekayasa ulang peristiwa lampau. Fotografi yang tajam dan kontras memberikan kesan suku Batak yang kuat dan tegas. Ilustrasi pena hitam putih dalam bentuk outline dan diberi arsir gelap terang dengan latar belakang warna krem seperti warna kertas yang menguning untuk memberi kesan klasik dan otentik. Buku visual menjadi sumber referensi yang mudah dipahami oleh orang-orang yang tertarik mempelajari kebudayaan, menyukai fotografi dan desain, khususnya suku Batak Toba di perantauan yang jauh dari kampung halaman..
\end{abstract}

Kata Kunci_ adat, batak, buku, toba, visual.

\section{PENDAHULUAN}

$\mathrm{S}_{\mathrm{n}}^{\mathrm{E}}$ EBAGAI salah satu suku terbesar di Indonesia, suku Batak memiliki adat istiadat beragam yang diturunkan dari nenek moyang. Selama ini adat istiadat tersebut diturunkan kepada penerusnya melalui mulut ke mulut. Namun, cara tersebut dapat berhenti di suatu masa ketika sudah tidak ada lagi yang dapat memberi informasi secara lisan mengenai adat tersebut.
Sehubungan dengan hal tersebut, adat istiadat perlu didokumentasikan agar tidak hilang termakan waktu dan jaman dalam suatu media. Adat yang didokumentasikan tersebut dapat tersimpan dengan baik dalam jangka waktu panjang untuk digunakan informasinya di kemudian hari saat tidak ada yang dapat memberikan informasi secara lisan.

Menurut Plato, bahasa visual merupakan bahasa universal yang mempunyai arti yang sama untuk setiap orang yang menerimanya. Efektivitas sejumlah indera untuk menerima rangsangan yakni sebagai berikut: indera penglihatan $83 \%$, indera pendengaran $11 \%$, indera penciuman $3,5 \%$, indera peraba $1,5 \%$, indera perasa $1 \%$ [1]. Dengan buku visual penyampaian informasi dapat lebih komunikatif menggunakan berbagai aspek seperti teks, fotografi, infografik, dan gambar ilustrasi untuk memudahkan pembaca dalam mempelajari adat istiadat suku Batak. Sifatnya yang kekal membuat buku visual dapat diarsipkan secara fisik maupun digital.

\section{A. Identifikasi Masalah}

1. Adat Batak merupakan salah satu kekayaan budaya bangsa Indonesia yang harus dilestarikan secara tertulis agar tetap kekal hingga generasi-generasi selanjutnya.

2. Dewasa ini, buku referensi tentang adat istiadat dan budaya suku Batak Toba semakin terbatas jumlah dan kualitasnya

3. Penyajian buku yang sudah ada kurang mampu mengakomodasi kebutuhan informasi secara visual.

\section{B. Rumusan Masalah}

Bagaimana membuat buku visual adat istiadat suku Batak Toba yang dapat mengakomodasi kebutuhan informasi dan visual pembaca agar dapat melestarikan adat istiadat suku Batak Toba?

\section{Batasan Masalah}

1. Pengetahuan tentang adat istiadat suku Batak Toba sebagai sub suku Batak yang paling banyak jumlahnya dibandingkan dengan sub suku Batak lainnya.

2. Dengan terbatasnya waktu, maka pembahasan difokuskan terhadap adat istiadat suku Batak Toba yang diterapkan di Pulau Samosir. Pemilihan Pulau Samosir didasari oleh pertimbangan bahwa daerah tersebut merupakan asal mula penyebaran suku Batak Toba.

3. Media yang digunakan dalam perancangan tersebut adalah buku visual dalam bentuk cetak. Hal ini agar 
pembaca memiliki pengalaman tersendiri saat menyentuh buku tersebut secara jelas dan detail dengan ukuran buku sebenarnya, dibandingkan bila melihat buku digital.

4. Konten pada buku visual mencakup pembabakan yang sudah ditentukan batasannya, terdiri dari 6 topik utama yaitu sejarah, marga, upacara adat, ulos, rumah adat, dan kesenian. Topik tersebut dipilih berdasarkan hasil observasi, dimana adat-adat tersebut masih terus dilakukan hingga saat ini oleh penerusnya. Namun, buku visual tidak mencakup bahasa Batak karena lingkup bahasa Batak yang sangat luas.

5. Stakeholder perancangan ini adalah penerbit buku KPG (Kepustakaan Populer Gramedia) dimana penerbit tersebut memang fokus dalam penerbitan buku-buku sains dan humaniora dengan memadukan bisnis dan kegiatan sosial.

D. Tujuan

1. Buku visual adat istiadat suku Batak Toba menjadi sebuah bentuk pelestarian salah satu budaya Indonesia secara fisik dan tertulis.

2. Buku visual adat istiadat suku Batak Toba sebagai sumber informasi dan referensi pertama bagi orang Batak maupun orang di luar suku Batak yang tertarik dengan adat dan budaya Batak Toba bila ingin membuat mediamedia turunan yang berkaitan dengan adat Batak Toba.

\section{URAIAN PENELITIAN}

\section{A. Landasan Teori}

1) Batak

Tanah Batak meliputi daerah seluas $50.000 \mathrm{~km} 2$, berpusat di danau Toba dan sebagian dari pegunungan Bukit Barisan di provinsi Sumatera Utara. Tanah Batak ialah Kabupaten Tapanuli Utara, Tengah, dan Selatan (sebelum pemekaran). Wilayah yang berbatasan dengan Kabupaten Simalungun, Karo dan Aceh Tenggara berada di arah Utara, Kabupaten Simalungun, Asahan dan Labuhan Batu di arah Timur, sebelah selatan berbatasan dengan Provinsi Riau dan Sumatera Barat, dan di sebelah Barat terletak Lautan Hindia.

\section{2) Layout}

Layout adalah tata letak elemen-elemen desain terhadap suatu bidang dalam media tertentu untuk mendukung konsep/desain yang akan disampaikan [2]. Elemen penyusun layout untuk keperluan editorial terdiri dari (1) headline, (2) lead text, (3) stand first, (4) body copy, (5) subheads, (6) pull quotes, (7) caption, (8) folios, (9) panel, (10) gambar. [3]

3) Grid

Grid adalah alat bantu yang digunakan saat melayout. Grid mempermudah dalam menentukan letak elemen-elemen desain. Tujuan utama dalam penggunaan grid adalah untuk menciptakan keteraturan dan menghindari adanya kekacauan [4]. Elemen-elemen dalam sebuah grid, antara lain margin, flowlines, columns, modular, spatial zones, markers.

\section{4) Anatomi Buku}

Bagian-bagian penyusun buku secara umum terdiri dari cover, halaman preliminaries, bagian utama (isi), dan bagian postliminary [5].

5) Fotografi

Fotografi sebagai proses melukis/menulis dengan menggunakan media cahaya. Fotografi juga berarti proses atau metode untuk menghasilkan gambar atau foto dari suatu objek dengan merekam pantulan cahaya yang mengenai objek tersebut pada media yang peka cahaya. Jenis fotografi yang digunakan antara lain (1) still life, (2) lanskap, (3) potrait, (4) human interest, (5) jurnalistik, dan (6) digital imaging.

6) Ilustrasi

Ilustrasi memiliki 3 fungsi yaitu sebagai informasi, sebagai dekorasi dan sebagai komentar [6]. Elemen pada ilustrasi terdiri atas (1) garis,(2) bentuk, (3) warna, (4) tekstur, (5)ruang, dan (6) ukuran.

\section{7) Tipografi}

Tipografi memegang peranan sangat penting dalam keberhasilan suatu karya desain grafis, baik sebagai unsur utama atau pelengkap [7]. Faktor-faktor penting dalam tipografi antara lain (1) legibility, (2) readibility, (3) visibility, (4) clearity.

\section{B. Buku Sumber}

1) Buku Horas, dari Batak untuk Indonesia [8]

Buku "Horas, dari Batak untuk Indonesia" menjelaskan halhal yang berkaitan dengan Suku Batak secara umum hingga adat istiadatnya. Ruang lingkup yang diuraikan pada buku tersebut adalah upacara adat dan tata caranya, perkembangan marga, huruf aksara batak, ulos hingga tokoh-tokoh suku Batak yang berperan untuk kemajuan Indonesia.

2) Buku Folklore Batak Toba [9]

Buku ini memuat ungkapan-ungkapan yang sering diucapkan orang Batak baik dalam kesehariannya maupun saat pesta. Isi ungkapan folklor lisan yang ditulis dalam buku ini dapat berupa nasihat, kiasan, cerita, atau kritik tajam.

3) Buku Struktur Sosial dan Politik Batak Toba hingga 1945[10]

Buku ini membahas mengenai berbagai hal dalam kehidupan sehari-hari orang Batak. Kehidupan adat, sosial, agama, hingga sejarah. Cara pembahasan dalam buku ini sangat mendetail dimulai dari hal yang umum ke khusus. Di awal bab dibahas dari sejarah orang Batak, asal usul, kemudian ke pembahasan yang berkaitan dengan keseharian orang Batak seperti adat pernikahan, kekerabatan dengan sesama orang Batak, dan agama.

\section{4) Buku Art et Culture Batak/ Seni Budaya Batak [11]}

Buku ini membahas tentang seni dan budaya Batak seperti artefak-artefak, kesenian, dalam kaitannya dengan animisme dan dinamisme yang dahulu pernah ada dalam lingkungan Suku Batak. Buku ini kemudian diterjemahkan dalam versi bahasa Perancis, sehingga terbagi dalam dua bagian bahasa yaitu bahasa Indonesia dan bahasa Perancis.

\section{5) Buku Kain Ulos Danau Toba [12]}

Buku ini membahas tentang kain ulos Batak dari segi makna serta ragam jenisnya. . Latar belakang penulisan ini adalah mendokumentasikan kain ulos sebagai salah satu kain khas nusantara. Buku ini juga bekerja sama dengan pesona 
Indonesia dalam rangka meningkatkan aspek kepariwisataan Indonesia dari segi budaya.

\section{METODOLOGI PERANCANGAN}

\section{A. Metode Pengumpulan Data}

\section{1) Data Primer}

\section{a. Studi Etnografi}

Etnografi dilakukan Peneliti dari tanggal 28 September hingga 6 November 2017 untuk mengamati secara langsung kehidupan adat suku Batak Toba di Pulau Samosir dan mendapatkan data-data visual untuk konten buku.

b. Depth Interview

Melakukan wawancara mendalam dengan beberapa pihak antara lain:

1. Raja Adat di Balige dan Samosir yaitu Saut Tamba Tua, Mangiring Simbolon, Sudung Simbolon. Kegiatan ini untuk mengetahui tata upacara adat Batak Toba seperti perkawinan dan kematian.

2. Petenun kain ulos di Sitonggi-tonggi, Donganraja Tampubolon dan Pensa Simbolon. Kegiatan ini dilakukan untuk mengetahui jenis, fungsi, dan makna ulos.

3. Pemilik rumah adat dan pemahat gorga di Sitonggi-tonggi yaitu Boslin Nadeak dan Ridson Sitanggang. Kegiatan ini untuk Mengetahui bagian dan makna rumah adat batak (Rumah Bolon)

4. Guru musik di Pangururan, Zico Mardo. Kegiatan ini untuk Mengetahui macam-macam musik tradisional batak serta maknanya.

5. Dosen Antropologi UI (Universitas Indonesia), Dra. Sri Murni, M. Kes, untuk mengetahui mengenai adat istiadat secara umum dan kehidupan budaya dan sosial masyarakat saat ini yang berkaitan dengan adat istiadat.

6. Penerbit Gramedia Pustaka Utama, yaitu Dionisius Wisnu (PR Gramedia Pustaka Utama) dan Claudia Von Nasution (Editor Akuisisi Gramedia Pustaka Utama). Wawancara ini untuk mengetahui selera pasar buku saat ini khususnya pasar buku visual non fiksi (budaya) dan mengetahui sistematika kriteria penulisan buku yang benar.

2) Data Sekunder

Data sekunder digunakan sebagai data pembanding untuk melengkapi konten buku, antara lain:

a. Buku sumber yang membahas tentang adat istiadat dan budaya Batak Toba

b. Data yang didapat dari internet berupa artikel, berita, dan dokumentasi foto dan video tentang adat istiadat dan budaya Batak Toba.

\section{B. Kerangka Penelitian}

Kerangka penelitian dapat dilihat pada Gambar 1.

\section{KONSEP DESAIN}

\section{A. Konsep Luaran}

Keyword dalam perancangan ini adalah detail, komunikatif, dan modern. Konten yang disajikan dalam buku harus detail. Aspek detail sesuai dengan kebutuhan informasi target audiens

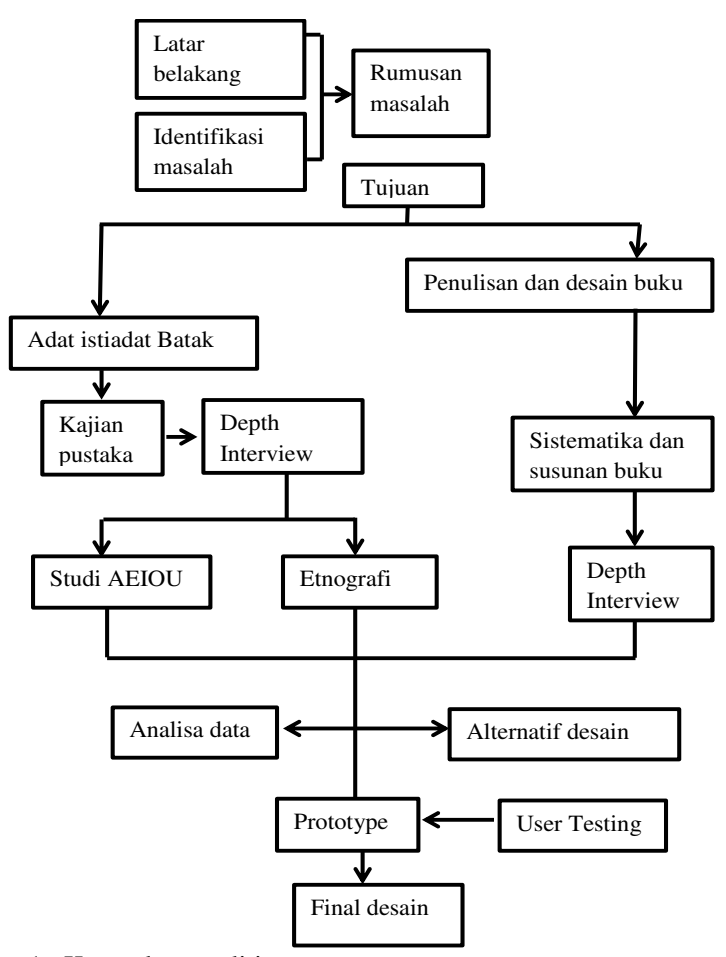

Gambar. 1. Kerangka penelitian

yang berpendidikan dan menyukai budaya untuk aktualisasi diri. Dengan menyajikan informasi yang detail, pembaca dapat merasakan ikatan emosional dengan buku tersebut. Karena itulah, di buku Batak Toba Lebih Dekat tidak hanya menceritakan adat yang terjadi di jaman dahulu, tetapi juga menceritakan bagaimana adat yang terjadi di masa sekarang. Pembaca dapat memahami bahwa adat sebenarnya terus terjadi di sekitarnya.

Bahasa dan elemen visual komunikatif agar pembaca mudah memahami isi buku. Istilah-istilah dalam bahasa Batak yang tergolong rumit untuk orang awam juga harus diterjemahkan ke bahasa yang lebih mudah dipahami.

Konsep modern ditampilkan pada desain layout yang clean dan minimalis. Konten yang bersifat tradisional dan otentik disajikan ke dalam bentuk yang lebih modern agar terlihat lebih elegan dan bermartabat tinggi. Agar tidak menghilangkan unsur etnik dan kultural dari buku ini, maka desain yang modern akan dipadukan dengan corak dan ornamen khas Batak yaitu gorga. Ketiga hal tersebut disimpulkan menjadi sebuah big idea yaitu Telisik Toba yang berarti mencari tahu lebih dalam dan dekat dengan Batak Toba.

\section{B. Konten Buku}

Struktur buku dan konten untuk buku visual Batak Toba terdiri dari 6 topik utama yang dipilih berdasarkan hasil observasi mengenai adat dan budaya yang masih dipertahankan, antara lain:

1. Cover (depan, belakang dan punggung buku)

2. Halaman judul

3. Copyright

4. Daftar isi

5. Halaman kata pengantar

6. Bab 1 - Sejarah

7. Bab 2 - Tutur

8. Bab 3 - Upacara Adat 
9. Bab $4-$ Ulos

10. Bab 5 - Rumah Adat

11. Bab 6 - Kesenian

12.Daftar pustaka

13.Indeks

14. Tentang penulis

\section{Grid}

Buku visual ini dilayout dengan menggunakan bantuan grid kolom. Dalam satu halaman terdapat 4 kolom. Kriteria desain sistem grid dalam perancangan buku visual ini adalah :

1. Margin atas : $35 \mathrm{~mm}$

2. Margin bawah : $35 \mathrm{~mm}$

3. Margin kanan : $35 \mathrm{~mm}$

4. Margin kiri : $35 \mathrm{~mm}$

5. Jumlah kolom : 8

6. Gutter : $7 \mathrm{~mm}$

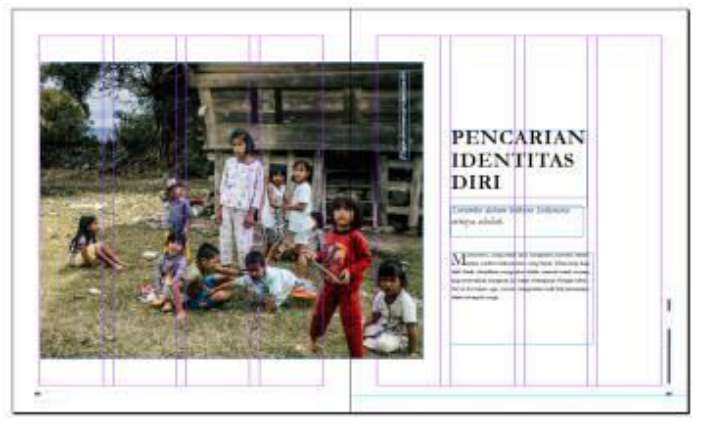

Gambar. 2. Grid 4 kolom

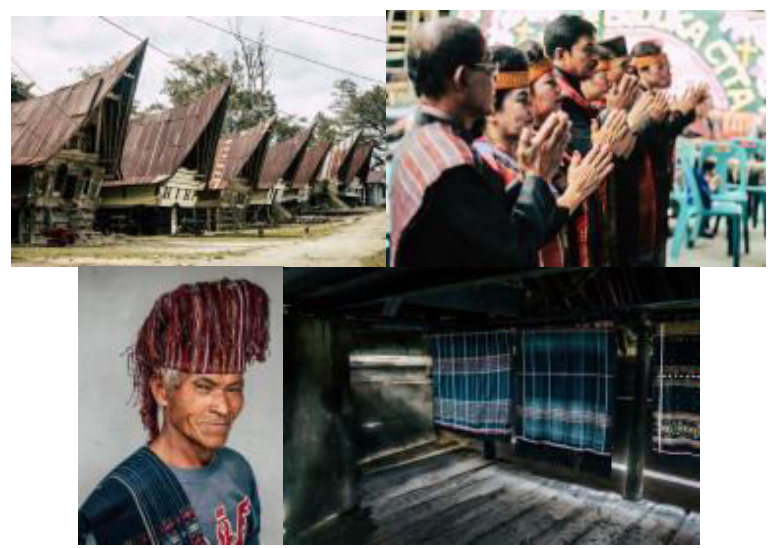

Gambar. 3. Fotografi still life \& lanskap, jurnalistik, potrait, dan digital imaging

\section{Gaya Bahasa}

Penyampaian informasi dalam buku visual ini banyak menggunakan kalimat naratif dan deskriptif. Kalimat naratif bersifat menceritakan suatu peristiwa atau suatu kisah. Sedangkan kalimat deskriptif lebih menggambarkan wujud suatu objek.

\section{E. Fotografi}

Jenis fotografi yang digunakan dalam perancangan ini adalah fotografi potrait, lanskap, still life dan jurnalistik. Fotografi jurnalistik untuk menggambarkan rangkaian proses kegiatan adat. Fotografi potrait untuk menggambarkan karakter dan ekspresi orang Batak Toba. Still life dan lanskap untuk menggambarkan keadaan artefak dan pemandangan alam di tanah Batak.

Kriteria untuk foto pada buku visual ini adalah tone warna hangat dengan sedikit tone dingin, kontras tinggi, dan tajam. Kriteria desain tersebut menggambarkan karakter orang Batak yang tegas dan kuat.

\section{F. Ilustrasi}

Ilustrasi merupakan elemen visual untuk mengisi bagian minor dalam buku yang digunakan untuk menggambarkan halhal yang tidak bisa disampaikan melalui fotografi seperti kisah sejarah ilustrasi buku Batak Kini dan Nanti dibuat dengan gaya ilustrasi hitam putih dengan pena. Gaya ilustrasi tersebut kembali populer dan identik dengan kesan vintage. Ilustrasi dibuat dengan outline dan diarsir untuk membuat bagian gelap terang pada objek gambar. Semua gambar pada buku Batak Toba Lebih Dekat juga harus dibuat dengan latar belakang warna krem untuk membedakan dengan halaman yang berisi foto.

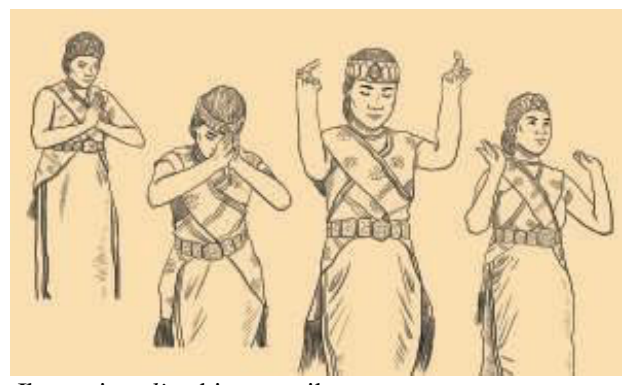

Gambar. 4. Ilustrasi outline hitam putih

\section{G. Tipografi}

Buku ini menggunakan font Garamond sebagai font utama untuk title (headline), subheadine, dan body text. Pemilihan font Garamond dikarenakan font serif ini memiliki kesan elegan dan modern. Font Montserrat digunakan sebagai font minor untuk mengisi bagian caption pada foto.

\section{H. Layout}

Elemen penyusun layout dalam buku terdiri dari beberapa hal seperti headline, lead text, subhead, body copy, pull quote, running head, stand first, dan gambar.

\section{Warna}

Buku ini tersusun dalam 3 warna utama yaitu merah, hitam dan putih. Sedangkan warna krem sebagai warna pendukung untuk beberapa bagian minor dalam buku. Tiga warna utama berkaitan dengan tiga banua dalam adat Batak antara lain, putih adalah banua ginjang atau surga, warna merah adalah banua tonga atau kehidupan nyata yang kita tempati, dan hitam adalah banua tolu atau kematian.

\section{J. Teknis Buku}

1. Ukuran : $25 \mathrm{~cm} \times 21 \mathrm{~cm}$

2. Jumlah halaman : 198 halaman

3. Penggunaan warna : full color

4. Jenis kertas isi : Garda Pat Kiara 150 gsm

5. Cover : Conorado

6. Binding : Jahit benang dan hardcover

7. Packaging : Slipcase packaging 


\section{HASIL DESAIN}

Hasil desain berupa konten teks, foto, dan ilustrasi yang diimplementasikan dalam buku visual berjudul "Batak Toba Lebih Dekat".

\section{A. Hasil akhir desain cover}

Foto orang tua dan guratan di wajahnya pada desain cover menggambarkan pengalaman kehidupan orang Batak yang beradat dari dahulu (nenek moyang) hingga saat ini. Selain itu, orang Batak juga selalu menghormati orang yang lebih tua dan dalam setiap kegiatan adat dimana orang tua harus selalu memberi berkat kepada anak-anaknya.

\section{B. Hasil akhir desain halaman preliminaries}

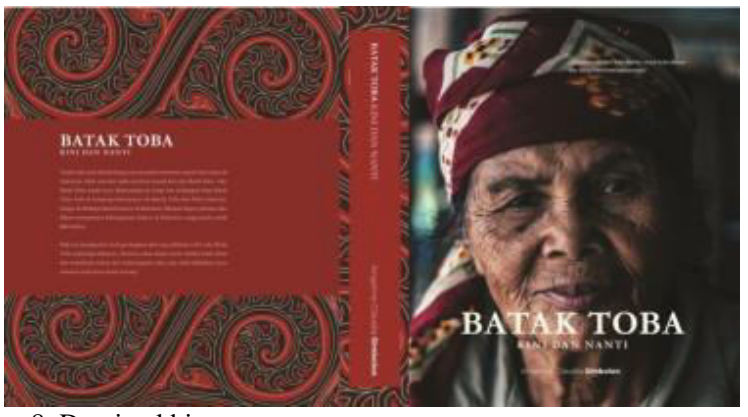

Gambar.8. Desain akhir cover

Halaman preliminaries terdiri dari halaman copyright, halaman daftar isi, halaman kata pengantar. Pada halaman preliminaries terdapat beberapa foto yang mewakili foto di halaman isi buku.

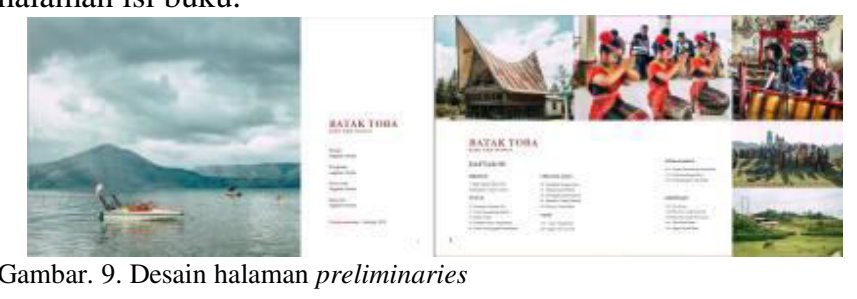

\section{Hasil akhir desain halaman cover bab}

Halaman cover bab terdapat foto dengan format landscape yang disertai dengan judul dan nomor bab.

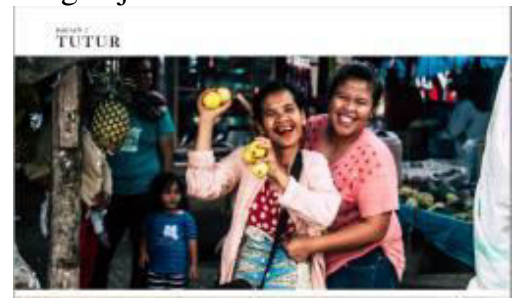

Gambar. 10. Desain cover bab

\section{Hasil akhir desain halaman isi}

Berikut ini beberapa layout yang mewakili halaman isi buku dapat dilihat pada Gambar 11.

\section{E. Hasil akhir desain packaging buku}

Packaging buku berbentuk slipcase dengan bahan yang tipis agar tidak menambah massa buku semakin berat. Cover pada packaging dibuat berbeda dengan cover buku, agar tidak terjadi pengulangan visual.

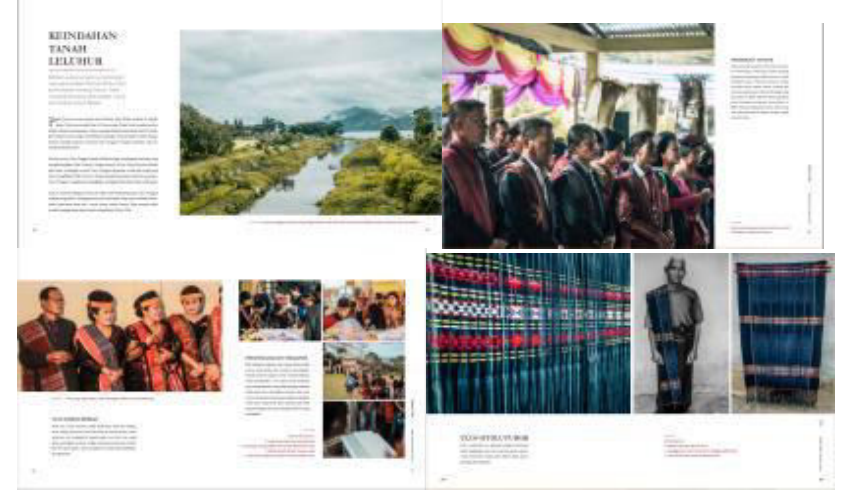

Gambar. 11. Desain halaman isi

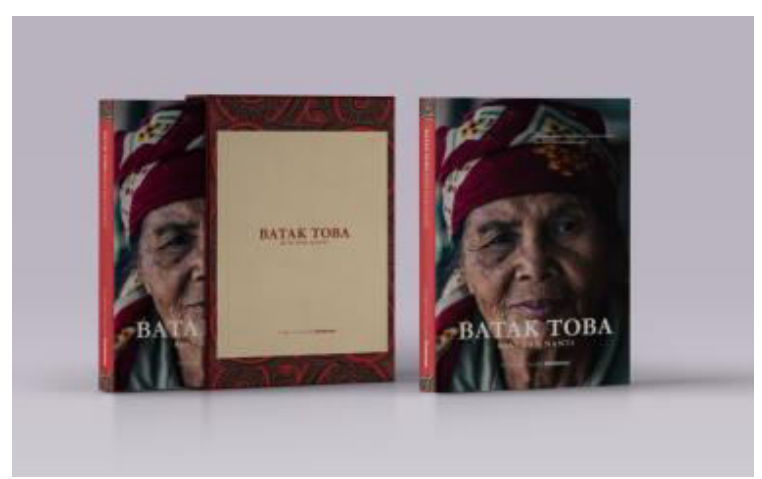

Gambar. 12. Packaging buku

\section{KESIMPULAN/RINGKASAN}

Buku visual adat istiadat suku Batak Toba sebagai media untuk melestarikan salah satu warisan budaya Indonesia ke dalam sebuah media tertulis sehingga adat istiadat tersebut tetap kekal dan dapat diturunkan informasinya ke generasi selanjutnya. Media buku visual dapat menyampaikan informasi secara lebih detail, dapat diarsipkan dan buku dapat menjadi sumber referensi pertama untuk media turunan lainnya.

Perancangan buku visual tentang adat istiadat Batak Toba ditujukan untuk orang-orang yang tertarik dengan kebudayaan suku Batak Toba dengan profil usia 35-40 tahun, suku Batak khususnya yang berada di perantauan, berpendidikan dan memiliki finansial yang cukup, namun tergolong orang yang sibuk.

Buku visual membahas 6 topik utama, meliputi sejarah, marga, upacara adat, rumah adat, ulos, dan kesenian. Untuk menunjang pembahasan tersebut, buku dilengkapi dengan elemen visual berupa foto dan ilustrasi. Buku diujicobakan kepada 3 orang user yang berbeda latar belakang untuk mendapatkan masukan demi pengembangan buku yang lebih baik.

Dalam perancangan ini perlu dilakukan konfirmasi ulang mengenai kebenaran konten kepada narasumber agar data menjadi lebih valid. Selain itu, pengembangan buku visual lebih lanjut dapat diarahkan ke aspek ilustrasi. Pengembangan konten yang lebih mendetail dapat dilakukan pada nama-nama marga Batak dan bahasa Batak yang cakupannya cukup luas.

\section{DAFTAR PUSTAKA}

[1] E. B. Prasetyo, "PERAN ILUSTRASI VISUAL DALAM 
PEMBELAJARAN," Maj. Ilm. PEMBELAJARAN, vol. 2, no. 2, Oct. 2006.

[2] S. Rustan, Layout Dasar dan Penerapannya. Gramedia Pustaka Utama, 2008.

[3] C. Caldwell and Y. Zappaterra, Editorial design: digital and print. china: Laurence King Publishing Ltd. , 2014.

[4] A. Jute, Grids : the structure of graphic design. RotoVision, 1996.

[5] W. Suwarno, Perpustakaan \& buku: wacana penulisan \& penerbitan. Yogjakarta: Ar-Ruzz Media, 2011.

[6] S. Jennings, The Complete guide to advanced illustration and design. Chartwell Books, 1987.

[7] D. Sihombing and W. Sunarto, Tipografi dalam Desain Grafis.
Gramedia Pustaka Utama, 2001

[8] B. Sianipar, Horas, Dari Batak Untuk Indonesia. Jakarta: Rumahan Indonesia, 2012.

[9] O. M. Sophar Simanjuntak, Folklor Batak Toba. Jakarta: Yayasan Pustaka Obor Indonesia, 2015.

[10] B. A. Simanjuntak, Struktur Sosial dan Sistem Politik Batak Toba Hingga 1945. Jakarta: Yayasan Pustaka Obor Indonesia, 2016.

[11] J. S. Hasibuan, Seni Budaya Batak. PT Jayakarta Agung Offset, 1985.

[12] T. Emir and S. Wattimena, Kain ulos Danau Toba: pesona kain Indonesia. Jakarta: PT Gramedia Pustaka Utama , 2017. 